\title{
Wake Measurements of a Multi-MW Wind Turbine with Coherent Long-Range Pulsed Doppler Wind Lidar
}

\author{
Yvonne KäSleR, StePHAn RAHM, AND Rudolf Simmet \\ Deutsches Zentrum für Luft- und Raumfahrt, Institut für Physik der Atmosphäre, Wessling, Germany \\ MARTIN KÜHN \\ Research Group Wind Energy Systems-ForWind, Center for Wind Energy Research, \\ University of Oldenburg, Oldenburg, Germany
}

(Manuscript received 15 April 2010, in final form 8 June 2010)

\begin{abstract}
Long-range Doppler wind light detection and ranging (lidar) measurements at a wind turbine were carried out for the first time. The turbine was of the type Areva M5000 and is located at a site near the coastline in Bremerhaven, in the northern part of Germany. This wind turbine is the prototype for the German offshore test site "alpha ventus" and has a rated power of $5 \mathrm{MW}$. Information about the ambient wind field before and after this multimegawatt wind turbine was obtained. In this paper the measurement technique is discussed and the results of measurements in the diurnal layer and in the stable nocturnal boundary layer are shown. The main focus of this work is to determine the reduction of the wind speed at certain distances downstream from the rotor.
\end{abstract}

\section{Measurement technique}

Lidar is a remote sensing technique that transmits a laser beam into the atmosphere and the backscattered light is detected. The pulsed Doppler wind lidar, which was used for the measurements in Bremerhaven, Germany, takes advantage of the fact that the center frequency of the received laser pulses is shifted compared to the outgoing pulses because of the Doppler effect, which occurs from backscattering on moving particles. This shift in frequency provides information about the line-of-sight (LOS) component (component in beam direction) of the wind vector. The Doppler lidar of the German Aerospace Center [Deutsches Zentrum für Luft- und Raumfahrt (DLR)] is based on a WindTracer transceiver unit of Lockheed Martin (which acquired Coherent Technologies, Inc. and its division CLR Photonics, Inc.; Köpp et al. 2004). It has been modified by the DLR and has been used for wind and turbulence measurements from the ground, as well as from

Corresponding author address: Yvonne Käsler, Deutsches Zentrum für Luft- und Raumfahrt, Münchner Str. 20, Oberpfaffenhofen, D-82234 Wessling, Germany.

E-mail: yvonne.kaesler@dlr.de its research aircraft in the past (Rahm and Smalikho 2008; Smalikho et al. 2005). The most important aspect was the addition of a scanner that makes different scan patterns at variable scan speeds possible. The measurement range on ground is between $500 \mathrm{~m}$ and $10 \mathrm{~km}$. The maximum range used for the measurements in Bremerhaven was $3 \mathrm{~km}$. The main system parameters and important information for data acquisition and processing are summarized in Table 1. The specifications of the lidar do not completely coincide with those discussed in Smalikho et al. (2005) because of modifications of the laser system.

Figure 1a shows a map of the area in Bremerhaven (using the software program OpenStreetMaps). The 2- $\mu \mathrm{m}$ lidar is located at a distance of about $1820 \mathrm{~m}$ northeast of the wind turbine M5000. Technical data of the wind turbine can be found in Table 2. Furthermore, it can be seen in Fig. 1a that there are other wind turbines in the measurement area. One of them is of the same type as the Areva Multibrid M5000. Two different scanning techniques to analyze the ambient wind field of the prototype of the Multibrid M5000 were carried out: azimuth scans (Fig. 1a) and elevation scans (Fig. 1b). For the azimuth scans, the elevation of the laser beam was constant and the azimuth angle was continuously changed. The duration of an azimuth scan was $15 \mathrm{~s}$ and the scan speed $2^{\circ} \mathrm{s}^{-1}$. For 
TABLE 1. The 2- $\mu \mathrm{m}$ lidar system parameters and data acquisition. FWHM is the full width at half maximum.

\begin{tabular}{ll}
\hline \hline Slave laser (Tm:LuAG) & \\
\hline Wavelength & $2.022 \mu \mathrm{m}$ \\
Repetition rate & $500 \mathrm{~Hz}$ \\
Pulse energy & $1.5 \mathrm{~mJ}$ \\
Pulse length (FWHM) & $0.5 \mu \mathrm{s}=75 \mathrm{~m}(0.5 \mu \mathrm{s} \times c \div 2)$ \\
& $c:$ speed of light \\
Telescope & Off-axis type \\
& Aperture: $108 \mathrm{~mm}$ at lidar \\
& with afocal setting \\
Scanner & Double wedge with \\
& variable speed \\
Measurement range & Maximum: $500 \mathrm{~m}$ to $>10 \mathrm{~km}$ \\
& Processed data: $500 \mathrm{~m}$ to $3 \mathrm{~km}$ \\
Data acquisition & $0.3 \mathrm{~m}$ \\
Sample length & $512 \times 0.3 \mathrm{~m}=154 \mathrm{~m}$ \\
Width of lidar & \\
range gates & 50 \\
Number of range gates & \\
in 3 km & Elevation scan: $14 \mathrm{~s}$ \\
Sampling rate between & Azimuth scan: $22 \mathrm{~s}$ \\
\hline two scans &
\end{tabular}

the elevation scans, the azimuth angle was not changed but the elevation was increased continuously. One single elevation scan measurement took $10 \mathrm{~s}$. The scan speed for these types of scans was $1^{\circ} \mathrm{s}^{-1}$. The great advantage of the measurements is that it is possible to obtain information about the airflow in front and behind the wind turbine at the same time. This is in contrast to wake measurements that were carried out previously with a focused continuous wave lidar system (Bingöl et al. 2010; Trujillo et al. 2010).

\section{Results}

Figure 2 shows two measurements of the ambient field of the Multibrid M5000 in the nocturnal boundary layer: one elevation scan (Fig. 2a) and one azimuth scan (Fig. 2b). The wind was blowing from the northeast direction, parallel to the laser beam. Atmospheric conditions were very stable when the measurements were taken. The turbulence intensity at hub height $(102 \mathrm{~m})$ upstream from the wind turbine was only $2.8 \%$. This means that the wake effects are expected to be very distinct (Barthelmie et al. 2003). To determine this turbulence intensity, the LOS velocity at a range of two rotor diameters upstream from the M5000 at hub height was observed for $10 \mathrm{~min}$. This corresponds to 46 scans or a time series with 46 values. The turbulence intensity I was then calculated as

$$
I=\frac{\sigma_{\mathrm{LOS}}}{\overline{\mathrm{LOS}}}
$$

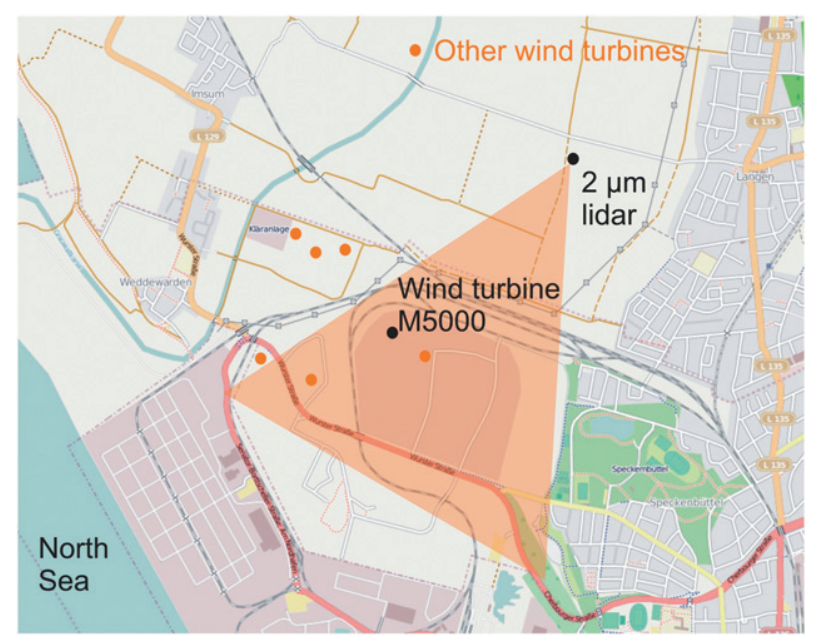

(a)

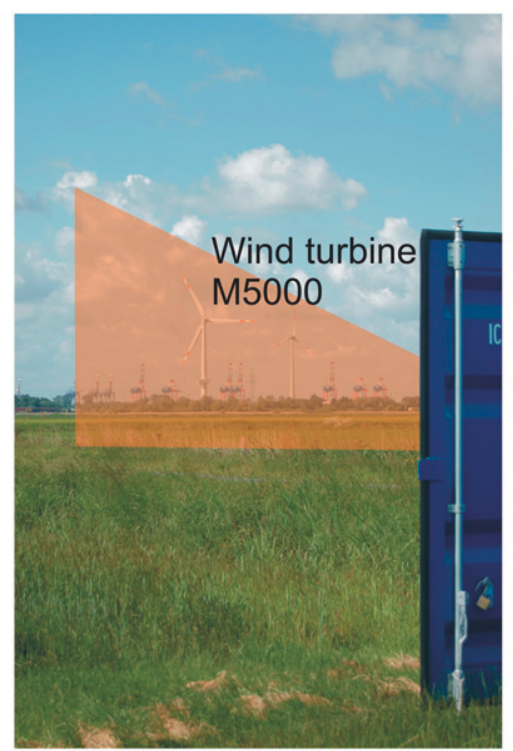

(b)

FIG. 1. (a) Map of the area in Bremerhaven with the position of the $2-\mu \mathrm{m}$ lidar and the wind turbines. A top view of an azimuth scan is given in the layout plan. (b) Side view of an elevation scan.

In this equation $\sigma_{\mathrm{LOS}}$ is the standard deviation and $\overline{\mathrm{LOS}}$ is the mean of the time series of the line-of-sight velocity (Stull 1988).

It needs to be considered that $\sigma_{\mathrm{LOS}}$ and $I$, which were determined by the lidar data, are significantly damped in comparison to anemometer measurements because of the long pulse length (cf. Table 1) of the pulsed wind lidar.

In Fig. 2a, the elevation scan through the rotor blades, only the wake effects of the prototype of the Multibrid M5000 can be seen. The range is the distance from the $2-\mu \mathrm{m}$ lidar, and the height reflects the elevation of the 
TABLE 2. Technical data of the M5000.

\begin{tabular}{ll}
\hline \hline Rotor diameter & $116 \mathrm{~m}$ \\
Hub height & $102 \mathrm{~m}$ \\
Length of a rotor blade & $62 \mathrm{~m}$ \\
Rated power & $5 \mathrm{MW}$ \\
Rated wind speed & $12 \mathrm{~m} \mathrm{~s}^{-1}$ \\
Maximum elevation height of the rotor & $164 \mathrm{~m}$ \\
Speed range of the rotor & $4.5-14.8 \mathrm{~min}^{-1} \pm 10 \%$ \\
\hline
\end{tabular}

laser beam. The position of the wind turbine and the wind direction are indicated in the picture. Between 1800 and $2600 \mathrm{~m}$, a decrease of the absolute value of the LOS component of the wind vector downstream from the Multibrid M5000 can be clearly observed. One rotor diameter $(116 \mathrm{~m}=1 D)$ downstream from the LOS velocity at hub height is reduced about $66 \%$ (the maximum of LOS velocity reduction) in comparison to the values upstream. After $7 D$ downstream (18\% reduction of the LOS velocity at hub height), the wind field only recovers very slowly. The velocity deficit downstream from the wind turbine is shown in Fig. 3. Because of data storage, the maximum range recorded in this measurement was $9 D$ downstream. At this range the reduction of the LOS velocity was $16 \%$ of the initial value. The black and red horizontal lines at a range between approximately 1700 and $2100 \mathrm{~m}$ in Fig. 2a indicate the areas where the laser beam hits the rotor blades. The backscatter of the blades is several orders of magnitude stronger than the atmospheric backscatter. The two lines represent two different rotor blades. The position of the wind turbine is at a range of $1823 \mathrm{~m}$. One needs to consider that the pulse length of the laser ( 0 to 0 ) is approximately $400 \mathrm{~m}$. When the beginning of the laser pulse hits the blades, there are $120 \mathrm{~m}$ in front of the turbine that are influenced by the blade because of the length of the laser pulse. With a symmetric laser pulse, one would expect that the black lines would end approximately $120 \mathrm{~m}$ after the turbine (i.e., at a range of approximately $1940 \mathrm{~m}$ ) when the end of the laser pulse hits a part of the blades. The laser pulse has a small tail containing little energy. Therefore, the horizontal lines are longer after the turbine than in front of the turbine. As a result, the shadows are approximately $400 \mathrm{~m}$ long and not only $240 \mathrm{~m}$. If not only part of the laser beam but the whole beam hits a blade, there is a black line behind the position of the turbine until the end of the measurement range (cf. Fig. 4). The different colors of the horizontal lines (black and red) therefore depend on the LOS velocity of the blades.

In Fig. $2 b$ an azimuth scan through the rotor blades can be seen. The width indicates the different azimuth angles. The elevation was $3.3^{\circ}$ for this measurement. This resulted in a scan through the rotor blades only somewhat above hub height. In comparison to Fig. 2a,

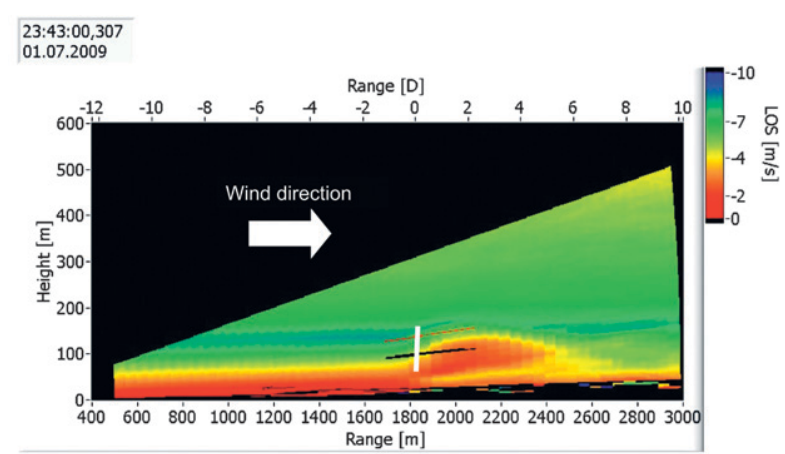

(a)

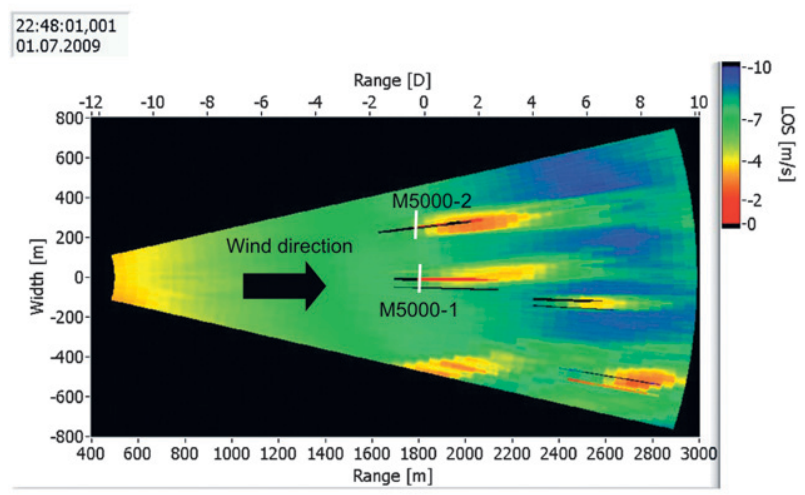

(b)

FIG. 2. (a) Results for the LOS component of the wind vector for an elevation scan through the rotor blades at night. The wind was blowing from the northeast parallel to the laser beam. Wind direction and position of the wind turbine are indicated in the figure. The white vertical line indicates the rotor disc. (b) Azimuth scan at night covering the ambient wind field of several wind turbines, including the M5000-1 prototype. The vertical white lines indicate the position of the rotor discs of M5000-1 and M5000-2.

this scan also covers the disturbance of the wind field by other wind turbines near the Multibrid M5000 prototype (M5000-1). The location of the different wind turbines can be estimated by the horizontal lines where the laser beam hits the rotor blades. There is another wind turbine (M5000-2) of the same type as M5000-1 and two turbines of different types. According to the horizontal lines, the laser beam hits one blade of the M5000-2 and

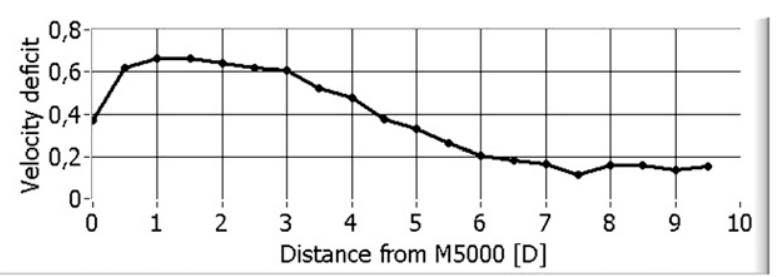

FIG. 3. Velocity deficit downstream from the wind turbine derived from the elevation scan in Fig. 2a. 


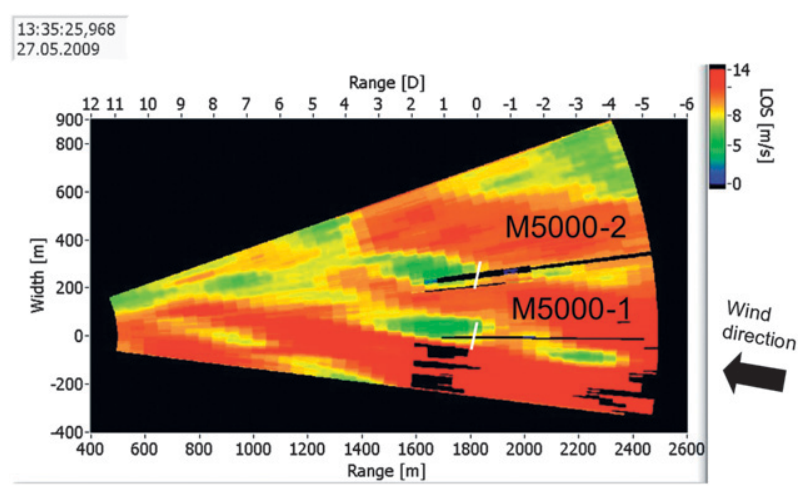

FIG. 4. Azimuth scan during daytime covering the ambient wind field of several wind turbines including the M5000-1 prototype. The white lines show the position of the rotor discs of M5000-1 and M5000-2.

two blades of the M5000-1. It needs to be considered that it is possible to hit one or more blades with one azimuth scan. It seems as if the turbines different from M5000 have a smaller effect on the wind field. But the shorter wakes are due to the elevation of the azimuth scan. This means that for these wind turbines, the wake is only cut by the scan. By analyzing the length of the wake of the M5000 wind turbines of this measurement, it can be found that the results correspond to the results of the elevation scan. Thus, it can be shown that for the measurements of the Multibrid M5000 turbines, the elevation scan as well as the azimuth scan captured the whole wake and not only cut it.

Figure 4 shows an azimuth scan during daytime with a turbulence intensity of more than $15 \%$, two rotor diameters upstream from the wind turbine at hub height. Notice that this measurement was taken on another day, and that the wind was blowing from a southwest direction parallel to the laser beam. As mentioned before, wake effects are supposed to be less distinct in a turbulent atmosphere (Barthelmie et al. 2003). This is evident when Fig. $2 \mathrm{~b}$ is compared to Fig. 4: the length of the wakes of the M5000 turbines is shorter in Fig. 4.

To sum up, it can be said that it has been shown that the $2-\mu \mathrm{m}$ Doppler lidar is a convenient tool for wind energy research and could help to improve the modeling of wind turbine wakes for single turbines, as well as for wind parks. A method for wake capturing has been developed.
We plan a detailed analysis for these measurements in the nocturnal boundary layer, and of measurements, were taken during daytime in a more turbulent atmosphere. Furthermore, a comparison with the Parallelized LargeEddy Simulation (LES) Model (PALM; Steinfeld et al. 2009; Raasch 2010) is already in preparation.

Acknowledgments. This work is done in the framework of the project "LIDAR-Development of LIDAR technologies for the German offshore test field" of the German Federal Environment Ministry (BMU; Contract 0327642). Thanks are given to Areva - Multibrid GmbH for providing access to the M5000 wind turbine and to the whole Lidar group of the Endowed Chair of Wind Energy at the University of Stuttgart, especially Juan José Trujillo for his helpful discussions and cooperation.

\section{REFERENCES}

Barthelmie, R. J., L. Folkerts, F. T. Ormel, P. Sanderhoff, P. J. Eecen, O. Stobbe, and N. M. Nielsen, 2003: Offshore wind turbine wakes measured by sodar. J. Atmos. Oceanic Technol., 20, 466-477.

Bingöl, F., J. Mann, and G. C. Larsen, 2010: Light detection and ranging measurements of wake dynamics. Part I: Onedimensional scanning. Wind Energy, 13, 51-61.

Köpp, F., S. Rahm, and I. Smalikho, 2004: Characterization of aircraft wake vortices by $2-\mu \mathrm{m}$ pulsed Doppler lidar. J. Atmos. Oceanic Technol., 21, 194-206.

Raasch, S., cited 2010: PALM-A parallelized LES model. [Available online at http://www.muk.uni-hannover.de/ raasch/PALM_group/ doc/app/index.html.]

Rahm, S., and I. Smalikho, 2008: Aircraft wake vortex measurement with airborne coherent Doppler lidar. J. Aircr., 45, 11481155.

Smalikho, I., F. Köpp, and S. Rahm, 2005: Measurement of atmospheric turbulence by $2-\mu \mathrm{m}$ Doppler lidar. J. Atmos. Oceanic Technol., 22, 1733-1747.

Steinfeld, G., S. Raasch, J. Tambke, J. Peinke, and D. Heinemann, 2009: Development of a large-eddy simulation (LES) model for modelling the far-wake effects of offshore windfarms. Proc. Euromech Colloquium 508 on Wind Turbine Wakes, Madrid, Spain, E.T.S.I. Industriales and Universidad Politécnica de Madrid, in press.

Stull, R. B., 1988: An Introduction to Boundary Layer Meteorology. Kluwer Academic Publishers, 666 pp.

Trujillo, J.-J., F. Bingöl, G. C. Larsen, J. Mann, and M. Kühn, 2010: Light detection and ranging measurements of wake dynamics. Part II: Two-dimensional scanning. Wind Energy, in press. 